\title{
Enhancing myogenic differentiation of pluripotent stem cells with small molecule inducers
}

\author{
Jihong Chen ${ }^{2}$ and Qiao $L i^{1,2^{*}}$
}

\begin{abstract}
Pluripotent stem cells are able to differentiate into many types of cell lineages in response to differentiation cues. However, a pure population of lineage-specific cells is desirable for any potential clinical application. Therefore, induction of the pluripotent stem cells with lineage-specific regulatory signals, or small molecule inducers, is a prerequisite for effectively directing lineage specification for cell-based therapeutics. In this article, we provide indepth analysis of recent research findings on small molecule inducers of the skeletal muscle lineage. We also provide perspectives on how different signaling pathways and chromatin dynamics converge to direct the differentiation of skeletal myocytes.
\end{abstract}

Keywords: Stem cells, Myogenic differentiation, Histone acetylation, Gene regulation, Nuclear receptor

Pluripotent stem cells, regardless of their origin, can generate skeletal myocytes. However, the frequency of these cells to differentiate into skeletal myocytes is relatively low in the absence of inducing signals. Different types of mouse stem cells have been used as model systems to study the molecular mechanisms of myogenic differentiation. The commitment of these stem cells into skeletal muscle lineage recapitulates the cellular and molecular processes occurring in the early embryogenesis. However, the central issue is how to preferentially enhance the specification of muscle lineage for potential therapeutics. Therefore, understanding on a molecular level of how different cell signaling pathways and chromatin dynamics converge to regulate myogenic differentiation is imperative for identifying suitable small molecule inducers to efficiently generate skeletal myocytes. To this end, mouse pluripotent stem cells will continue to serve as valuable model systems because of their close resemblance to skeletal myogenesis in vivo, and their ease of manipulation in experimental procedures.

\footnotetext{
* Correspondence: qiaoli@uottawa.ca

${ }^{1}$ Department of Cellular and Molecular Medicine, Faculty of Medicine, University of Ottawa, Ottawa, Ontario, Canada

${ }^{2}$ Department of Pathology and Laboratory Medicine, Faculty of Medicine, University of Ottawa, Ottawa, Ontario, Canada
}

\section{Retinoid signaling in early development}

In vertebrates, the proper distribution and metabolism of vitamin A is essential for normal embryonic development and growth [1]. Deficiency in vitamin A during early embryogenesis leads to congenital malformations and affects patterning and the development of many organ systems [2]. On the other hand, high concentrations of vitamin $\mathrm{A}$, or pharmacological concentrations of retinoid acid (RA), the most potent natural form of vitamin A, have severe teratogenic consequences. These diversified effects of RA are mediated by multiple levels of effectors, including the enzymes that control RA metabolism, the cytoplasmic RA-binding proteins, and the RA receptors [3].

The retinoic acid receptors (RAR) are ligand-inducible transcription factors that regulate the RA-responsive genes in a bimodal mode. The functions of RAR depend on the retinoid X receptors (RXR). RAR binds to DNA constitutively with RXR as a heterodimer regardless of ligand binding. In the absence of a ligand, the DNAbound RAR-RXR heterodimer functions as a transcription repressor by associating with the NCoR co-repressor complex. However, upon RA induction, it acts as an activator by recruiting the $\mathrm{p} 300$ coactivator complexes to activate gene transcription (Figure 1). As a result, NCoR is present at the RAR binding region in the absence of RA, whereas p300 is recruited to the region following RA signaling 


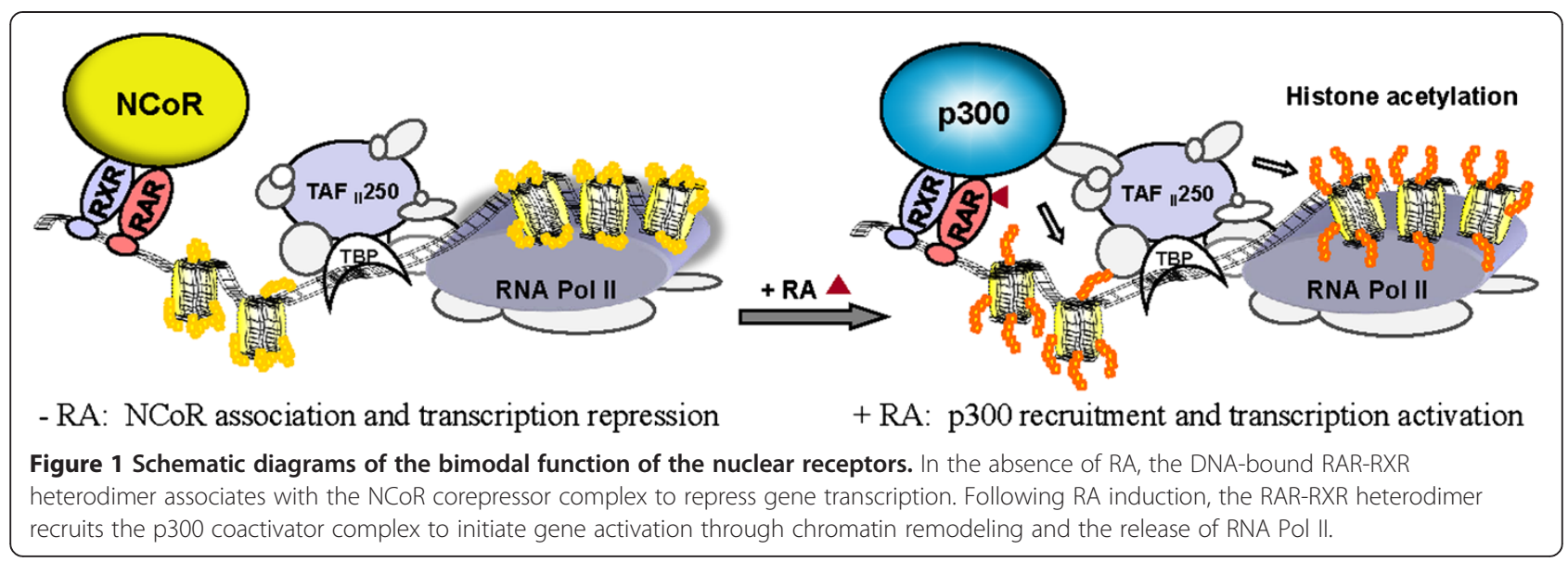

$[4,5]$. The RA-responsive promoters are often classified as pre-set, or poised promoters, because the TBP and Pol II complex associate to the TATA box constitutively [5].

In this bimodal model, the RAR-RXR dimer binds to the consensus DNA sequences, including the DR5 or DR2 motif, in which ligand induction is through the RAR, whereas RXR is generally considered a silent partner [6]. Nonetheless, in addition to RAR, the RXR is also able to dimerize with itself or with many other nuclear receptors to form permissive homodimers or heterodimers, in which the RXR is amenable to ligand activation.

Ligand-inducible nuclear receptors, including the glucocorticoid, thyroid, estrogen and androgen receptors, are a class of transcription factors that are capable of initiating dynamic chromatin changes in the promoter or enhancer regions by recruiting chromatin remodeling or modifying activities [7-13]. For example, the RA signaling is coupled with a global decrease in H3K27me3 modification, but an increase in histone acetylation, and is also coupled with the alterations in DNase I hypersensitive sites possibly through the dissociation of RAR-RXR dimer from SUZ12, and the recruitment of the histone acetyltransferase p300 [14-17].

There are three subtypes of RARs, namely RAR $\alpha$, RAR $\beta$ and RAR $\gamma$, which bind to all-trans and 9-cis RA [3]. The mice with each individual subtype of RAR knocked out are viable, appear to be normal, and have little developmental defects $[18,19]$. On the other hand, double RAR knockout mice exhibit a wide range of developmental abnormalities similar to vitamin A deficiency syndrome [20-23]. In fact, there is a large degree of functional redundancy between RARs which have important roles in many distinct stages of embryonic patterning and organogenesis [3].

The RXRs also consist of three subtypes, RXR $\alpha, \operatorname{RXR} \beta$ and RXR $\gamma$, which are activated by 9-cis RA [3]. The RXR knockout mice are well characterized as well. The RXR $\beta$ and RXRY null mice are viable and seem to be normal
$[24,25]$. However, RXR $\alpha$ null mutants die in utero and have myocardial and ocular malformations [24]. Most interestingly, the RXR $\alpha$ null mutants also exhibit developmental defects similar to fetal vitamin A deficiency syndrome [26,27]. Thus, RXR $\alpha$ is the main subtype involved in embryonic development.

Most interestingly, the compound RXR and RAR knockout mice recapitulate most of the developmental defects observed in the RAR double mutants [24,28], and RXR $\alpha-R A R$ is the major functional unit to mediate RA signaling during embryonic development [29]. Nonetheless, RXRs are also involved in many other signaling cascades and have the capacity to integrate multiple regulatory pathways as a ligand-bound receptor [30,31].

\section{Gene regulation and myogenic differentiation}

Gene transcription is regulated by an integrated action of many cis-regulatory elements including the long-range enhancers, proximal regulatory elements, and promoters. Complex interactions among this assemblage of regulatory elements are vital to the control of target gene transcription [32]. In eukaryotic cells, genomic DNA, including these cis-regulatory elements, is organized with histones and further packaged into a higher order chromatin structure [33]. This chromatin organization establishes hierarchical platforms on both local and global levels for regulatory-protein interactions during epigenetic inheritance, cell fate determinations, and ultimately, the control of gene expression programs [34].

To decree the complex interaction of these cisregulatory elements, the transcriptional coactivators or the HATs, recruited by sequence specific transcription factors play commanding roles in activating gene specific enhancers, and consequently, target gene transcription. For instance, active promoters are often associated with multiple histone modifications, whereas enhancers are associated with the HATs occupancy and histone acetylation [35-37]. Therefore, epigenetic and chromatin 
signatures have emerged as valuable marks to identify novel regulatory elements, in addition to DNA sequence motifs bound by potential transcription factors $[38,39]$.

Skeletal myogenesis is a highly ordered process coordinated by multiple myogenic regulatory factors, such as Myf5, MyoD, myogenin, and Mrf4 [40]. While Myf5 and MyoD activate muscle-specific gene expression and commit the progenitor cells into skeletal muscle lineage, myogenin and Mrf4 largely regulate the late stage of myogenic differentiation, such as the fusion of myoblasts into myotubes [41]. Upstream of Myf5, the Wnt signaling and Shh from the dorsal neural tube and notochord act, respectively, as the positive regulators of Myf5 gene expression, whereas MyoD gene expression depends on Pax3 and Myf5 [42]. Additionally, genetic evidence in the mouse and ES cell model systems has established that the expression of Myf5 and MyoD genes depends exclusively on the HAT activity of p300 [43].

\section{Stem cells}

Stem cells are excellent model systems for the studies of molecular mechanisms of cellular differentiation because of their abilities to differentiate into virtually all cell types in vitro. There are embryonic stem (ES) cells, adult stem (AS) cells, and induced pluripotent stem (iPS) cells, based on their derivative origins. The first evidence for the pluripotent nature of embryonic cells was obtained from studies of mouse embryonal carcinoma (EC) cells.

These EC cells, subcloned from teratocarcinomas, can be stably maintained as adherent cells and proliferate indefinitely in the tissue-culture dishes [44]. When cultured in the Petri dishes, they readily form cell aggregates which contain stem cells at the central part surrounded by epithelial cells. These cell aggregates, known as embryoid bodies (EBs), can develop extensive cavities and various cell types when subsequently grown as adhesive cultures [45]. For several decades, these EC cells have served as valuable model systems for the studies of early development and cellular differentiation, and paved the way for the isolation and establishment of mouse ES cells. Although, the pluripotent EC cells are much less used nowadays, they remain a useful model for the identification of small molecule inducers for myogenic differentiation [46].

\section{RA signaling and myogenic differentiation}

One valuable model system for mechanistic studies of early development is the pluripotent P19 cell line. Isolated from an experimental teratocarcinoma, it exhibits a typical EC morphology and normal karyotype [47]. Like other EC cell lines, these P19 cells can grow in tissue-culture dishes as undifferentiated cells indefinitely, and differentiate into cell lineages of all three germ layers. More importantly, they are amenable for genetic manipulation to incorporate and express ectopic genes, and for selecting subclones and transfected stable clones which retain their ability to differentiate.

When grown in Petri dishes, the P19 cells readily form EBs. Mesoderm specification occurs at the early stage of EB formation, coinciding with an up-regulation of Brachyury $\mathrm{T}$, a member of the T-box family of transcription factors [48]. However, EB formation per se does not lead to myogenic differentiation of the P19 stem cells, which requires additional inducing signals. When induced with small molecules, such as dimethyl sulfoxide (DMSO) or all-trans retinoic acid (RA), during EB formation, the P19 cells commit into the skeletal muscle lineage at a low frequency $[49,50]$. However, using combination of inducers, such as treating the EBs with both DMSO and RA, significantly increases the myogenic conversion of P19 stem cells [51].

The efficacies of P19 myogenic differentiation are influenced by the concentration of RA and the time line of treatments. Cells exposed to high RA concentrations $\left(>10^{-7} \mathrm{M}\right)$ develop into neurons and astrocytes, whereas EBs formed at the low concentrations $\left(<10^{-7} \mathrm{M}\right)$ differentiate into striated muscle [52]. The working concentration of RA for myogenic differentiation is typically around 5-30 nM, [46,53]. Nevertheless, the ability of P19 cells to generate skeletal myocytes is also influenced by other factors in the serum, and EB formation is a prerequisite for myogenic differentiation in these pluripotent cells [54].

Another valuable model system for mechanistic studies of myogenic differentiation is the mouse ES cells. They were first isolated in the early 1980s, from blastocysts grown on feeder-layer of division-incompetent mouse fibroblasts cells $[55,56]$. These ES cells express all markers of the EC cells, and can differentiate extensively in vivo and in vitro. The conditions for ES cell to differentiate in vitro are, in essence, the same as for the EC cells, depending on the process of EB formation [57]. However, the ES cells need to be maintained in inhibitory conditions to retain the undifferentiated state, because they are prone to spontaneous differentiation $[58,59]$. When grown in suspension culture without inhibitors, ES cells readily form EBs and consequently differentiate.

The early events of embryonic myogenesis are also closely recapitulated by EB differentiation of the ES cells into skeletal muscle lineage [60]. RA is also able to enhance the myogenic differentiation of ES cells. Specifically, RA affects the differentiation of ES cells into skeletal myocytes in a time- and concentration-dependent manner. Similar to the pluripotent P19 EC cells, high concentrations of RA $\left(>10^{-7} \mathrm{M}\right)$ induce neuronal differentiation of the ES cells, but suppress myogenic differentiation. Treatments of the EBs with low concentrations of RA $\left(<10^{-7} \mathrm{M}\right)$ at the stage of EB formation, enhance skeletal myogenesis, but inhibit cardiomyogenesis [61]. On the other hand, when low concentrations of RA are administered at the late 
stage of differentiation, skeletal myogenesis is inhibited, but cardiomyogenesis is enhanced [61].

Genetic manipulation has also been employed as an approach to induce myogenic differentiation of the ES cells. The premyogenic factor Pax3 plays an important role in embryonic muscle formation, acting upstream of muscle-specific gene program $[41,62]$. On the other hand, Pax7 is important for the maintenance of the muscle satellite cells [63-65]. Ectopic expression of Pax3 during EB differentiation enhances mesoderm formation and increases the myogenic potential of Pax3-induced ES cells [66]. Similarly, over-expression of Pax7 promotes the expansion of myogenic progenitors which possess muscle regeneration potentials [67]. Nonetheless, activating the myogenic signaling pathway with small molecular inducers, which can be easily administered into, or withdrawn from differentiation media, to direct myogenic specification remains a practical and appealing approach in view of potential cell-based therapies.

\section{Bexarotene as an efficient inducer of myogenic differentiation}

RXR is critical for the early stages of embryonic development $[24,26,27]$. A recent study has identified bexarotene, a RXR-selective ligand, to be an effective inducer for enhancing myogenic differentiation in the pluripotent stem cells [46]. Interestingly, the RXR selective ligand enhances myogenic differentiation in a concentration-dependent manner. The range of bexarotene working concentration is wide, $10-1000 \mathrm{nM}$, which reflects the kinetics of ligand affinity for the receptor [46]. More importantly, high concentrations of bexarotene do not inhibit the differentiation of pluripotent stem cells into skeletal muscle lineage [46]. This is in stark contrast to the narrow concentration range of RA on myogenic differentiation in vitro [46].

During P19 myogenic differentiation, RA increases the expression of mesoderm factors Meox1 and Pax3 [53]. Although both Meox1 and Pax3 are important for myogenesis, over-expression of Meox1 per se is not sufficient to induce P19 myogenic differentiation $[68,69]$. Interestingly, bexarotene increases the transcript levels of Meox1 with a greater efficacy than RA, whereas RA has a larger impact on Pax3 gene expression than bexarotene [46]. Nonetheless, the temporal expression of muscle-specific gene program in bexarotene-enhanced P19 myogenic differentiation is similar to myogenesis in vivo, and the RXR ligand acts as an effective inducer for the specification of skeletal muscle lineage [46]. It is worth noting that bexarotene has efficacies comparable to RA at converting the P19 stem cells into muscle lineage [46]. While RA may enhance skeletal myogenesis by expanding the progenitor population [53], bexarotene appears to affect germ layer fate determinations, and more specifically, promote mesoderm differentiation [46].
ES cells respond to RA poorly with respect to myogenic differentiation, i.e., RA has a very low efficacy at converting the ES cells into skeletal muscle lineage [46]. DMSO is not suitable for ES cell differentiation due to its toxicity to the cells. However, bexarotene alone is able to specify the ES cells into muscle lineage at a relatively high efficacy [46]. Thus, bexarotene is a much more effective inducer than RA to enhance the differentiation of ES cells into skeletal muscle lineage [46]. In addition, bexarotene is much more effective at inducing the transcripts of mesoderm factor Meox1 than RA in the ES cells, but is less efficient at the augmentation of Pax3 transcripts [46].

The finding of bexarotene to be a more efficient inducer than RA for myogenesis in the ES cell system is novel and significant [46]. In the ES cells, bexarotene alone is able to induce the expression of early differentiation marker Meox1, whereas RA depends on additional inducers to activate Meox1 expression (Figure 2). Thus, bexarotene may enhance the commitment of skeletal muscle lineage by fine-tuning the premyogenic transcriptional networks which favor the activation of the downstream myogenic program. Comprehensive systematic studies, such as RNA-seq analyses, will uncover additional early gene networks activated by RXR-specific signaling during mesoderm differentiation, identify novel early regulators of myogenic differentiation, and determine the molecular mechanisms by which the RXR agonist acts as an effective inducer of myogenic differentiation in the ES cells.

\section{Histone acetylation and myogenic enhancers}

A long-range RAR binding site has been identified at the Pax3 locus [53]. Both RAR and RXR bind to this locus during the early stage of myogenic differentiation regardless of RA signaling, as determined by a real-time PCR based chromatin immunoprecipitation (ChIP) assay [46]. More importantly, the association of transcriptional coactivator p300 with this RXR-RAR binding site increased markedly following RA induction [46]. In addition, p300 is detected at a Myf5 early enhancer at the early stage of myogenic differentiation by ChIP assay [70]. Thus, the Myf5 early enhancer is also directly regulated by $\mathrm{p} 300$.

The association of p300 to the Pax3 locus depends on the ligand-bound RAR in an on-and-off mode, increased about 15-fold after RA induction [46]. In contrast, the occupancy of p300 at the Myf5 early enhancer, which does not harbor a RAR binding site, increased only about 2-fold following RA signaling [70]. Interestingly, RA also increased the occupancy of $\beta$-catenin at the Myf5 enhancer by about 20-fold [70]. Nevertheless, histone acetylation increases at both the Pax3 locus and the Myf5 enhancer after RA induction (Figure 2). Therefore, RA regulates myogenic differentiation through p300- 


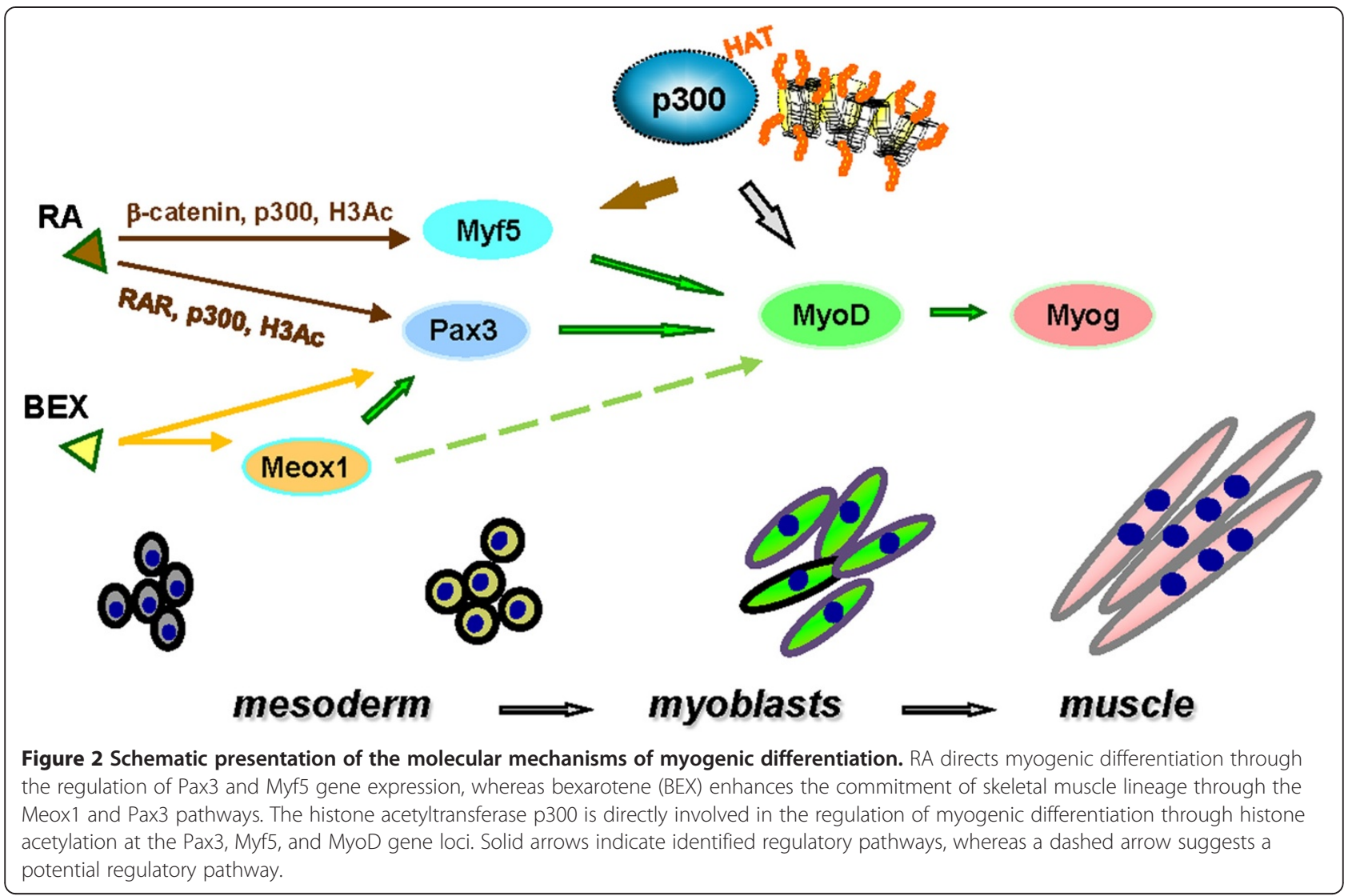

instigated histone acetylation in either DNA-bound RAR dependent or independent fashion.

In the differentiating myoblasts, the association of p300 to the MyoD enhancer is stepwise enriched at different regulatory regions, which positively correlates with increased histone acetylation in a discrete pattern [71]. Thus p300 is also directly involved in the early regulation of MyoD gene expression through specific histone acetylation (Figure 2). Nevertheless, the epigenetic marks for bexarotene-activated transcriptional networks or what transmit RXR specific signaling in myogenic differentiation remain to be determined. A comprehensive and systematic analysis by ChIP-seq will identify additional p300-dependent myogenic enhancers and uncover novel epigenetic marks to delineate the roles of p300 and histone acetylation in nuclear receptor-regulated stem cell differentiation.

\section{Cell-based therapeutics}

Many diseases and conditions, including muscular dystrophy, aging, cancer, inflammation, starvation, AIDS, congestive heart failure and chronic obstructive pulmonary diseases, can cause muscle wasting disorders, which can be extremely debilitating and lead to serious physical disabilities. It would be difficult to use differentiated skeletal myocytes for tissue transplantation and muscle regeneration, due to the unique architecture of skeletal muscle tissue. Thus, muscle repair or regeneration may be best achieved through the enrichment or transplantation of the progenitor cells which are already committed to the muscle lineage but not yet fully differentiated into skeletal myocytes. However, many challenges remain regarding the efficacy of myogenic specification. Issues to note are what type of stem cell is the best source to generate the progenitor cells and what is the best strategy to enrich the desired progenitor cells for potential clinical application.

More importantly, the transplanted progenitors must supplement to both the muscle fibers and the muscle stem cell pool in a successful long term therapy for skeletal muscle regeneration or repair. Muscle satellite cells appear to be an idea cell source for muscle regeneration, because following transplantation, they not only generate muscle efficiently, but also replenish the satellite cell pool $[72,73]$. However, their therapeutic potential is restricted by their relatively low abundance in muscle. In addition, the in vivo regeneration capacity of these satellite cells is greatly reduced following in vitro expansion [74]. Finally, in the severe cases of muscular dystrophy, the regenerative source of satellite cells is often exhausted [75].

On the other hand, the ES cells can be unlimitedly expanded in tissue culture, while maintaining their potential 
for pluripotent differentiation. Moreover, ES-derived myogenic progenitors can be seeded in the muscle stem cell compartment [66,67]. Thus, ES cell-based muscle regeneration has some unique advantages. However, use of ES cells in muscle wasting disorders is curtailed by the low frequency of myogenic specification in the cultures and the difficulty of identifying and isolating the progenitor cells. The low frequency of ES cells to commit into skeletal muscle lineage is mostly due to the low efficiency of mesoderm formation during EB-differentiation in the absence of inducing signals.

To harness the potential of ES cells in muscle regeneration, we need to identify small molecule inducers that are capable of efficiently committing the ES cells into the skeletal muscle lineage. Attempts at using RA in ES cell cultures have yielded poor results, while the RXR ligand appears to be a better inducer for myogenic differentiation. However, the mechanisms involved have not yet been fully determined. A comprehensive knowledge of the differentiation cues in ES cultures and a better insight into the regulation of myogenic pathway in vivo will help us identify additional small molecule inducers and develop the optimal protocols to generate sufficient amount of myogenic progenitors for muscle regeneration or repair.

Small molecule inducers have been used to reprogram somatic cells, to maintain induced pluripotent states, and to directly control lineage specification. They also have the potential to control the endogenous cell populations for regeneration purposes. The advance of regenerative medicine will benefit tremendously from a deep understanding of chemical biology, and a better comprehension of the signaling pathways and the molecular mechanisms involved in cell fate determinations.

\section{Conclusions}

Pluripotent stem cells possess a tremendous potential for the treatment of muscle-related diseases, because of their capacities to differentiate into the skeletal muscle lineage. However, small molecule inducers are required to direct the myogenic differentiation in vitro with an efficacy appropriate for viable cell-based therapies. Recent studies have uncovered the power of RXR-selective ligand to commit the ES cells into skeletal muscle lineage. Concerted systematic studies using stem cell differentiation as a model system will uncover novel early regulators and epigenetic marks important for myogenic differentiation. Pharmacological, or small molecule approaches to alter chromatin landscape for high efficiency of differentiation can then be identified. We will be able to develop non-toxic protocols with the optimal combination of inducers and conditions to commit the muscle lineage in view of generating muscle progenitors for clinical applications.

\section{Abbreviations}

AS cells: Adult stem cells; ChIP: Chromatin immunoprecipitation; ES cells: Embryonic stem cells; iPS cells: Induced pluripotent stem cells; RAR: Retinoic acid receptor; RXR: Retinoid X receptor; RA: Retinoic acid.

Competing interests

The authors declare that they have no competing interests.

\section{Authors' contributions}

JC and QL drafted the manuscript. Both authors read and approved the final manuscript.

\section{Acknowledgements}

This work was supported by a grant from the Natural Sciences and Engineering Research Council of Canada.

Received: 12 June 2013 Accepted: 16 August 2013

Published: 9 October 2013

\section{References}

1. Niederreither K, Dolle P: Retinoic acid in development: towards an integrated view. Nat Rev Genet 2008, 9:541-553.

2. Wilson $J G$, Roth $C B$, Warkany $J$ : An analysis of the syndrome of malformations induced by maternal vitamin A deficiency. Effects of restoration of vitamin $\mathrm{A}$ at various times during gestation. Am J Anat 1953, 92:189-217.

3. Chambon $\mathrm{P}$ : The nuclear receptor superfamily: a personal retrospect on the first two decades. Mol Endocrinol 2005, 19:1418-1428.

4. Folkers GE, van der Burg B, van der Saag PT: Promoter architecture, cofactors, and orphan receptors contribute to cell-specific activation of the retinoic acid receptor beta2 promoter. J Biol Chem 1998, 273:32200-32212.

5. Higazi A, Abed M, Chen J, Li Q: Promoter context determines the role of proteasome in ligand-dependent occupancy of retinoic acid responsive elements. Epigenetics 2011, 6:202-211.

6. Kurokawa R, DiRenzo J, Boehm M, Sugarman J, Gloss B, Rosenfeld MG, Heyman RA, Glass CK: Regulation of retinoid signalling by receptor polarity and allosteric control of ligand binding. Nature 1994, 371:528-531.

7. Li Q, Imhof A, Collingwood TN, Urnov FD, Wolffe AP: p300 stimulates transcription instigated by ligand-bound thyroid hormone receptor at a step subsequent to chromatin disruption. EMBO J 1999, 18:5634-5652.

8. Li Q, Sachs L, Shi YB, Wolffe AP: Modification of Chromatin Structure by the Thyroid Hormone Receptor. Trends Endocrinol Metab 1999, 10:157-164.

9. Li Q, Wrange O: Accessibility of a glucocorticoid response element in a nucleosome depends on its rotational positioning. Mol Cell Biol 1995, 15:4375-4384

10. Li Q, Wrange O: Translational positioning of a nucleosomal glucocorticoid response element modulates glucocorticoid receptor affinity. Genes Dev 1993, 7:2471-2482

11. John S, Sabo PJ, Johnson TA, Sung MH, Biddie SC, Lightman SL, Voss TC, Davis SR, Meltzer PS, Stamatoyannopoulos JA, Hager GL: Interaction of the glucocorticoid receptor with the chromatin landscape. Mol Cell 2008, 29:611-624.

12. Schild C, Claret FX, Wahli W, Wolffe AP: A nucleosome-dependent static loop potentiates estrogen-regulated transcription from the Xenopus vitellogenin B1 promoter in vitro. Embo J 1993, 12:423-433.

13. Wang Q, Carroll JS, Brown M: Spatial and temporal recruitment of androgen receptor and its coactivators involves chromosomal looping and polymerase tracking. Mol Cell 2005, 19:631-642.

14. Gillespie RF, Gudas LJ: Retinoid regulated association of transcriptional co-regulators and the polycomb group protein SUZ12 with the retinoic acid response elements of Hoxa1, RARbeta(2), and Cyp26A1 in F9 embryonal carcinoma cells. J Mol Biol 2007, 372:298-316.

15. Lee ER, Murdoch FE, Fritsch MK: High histone acetylation and decreased polycomb repressive complex 2 member levels regulate gene specific transcriptional changes during early embryonic stem cell differentiation induced by retinoic acid. Stem Cells 2007, 25:2191-2199.

16. Bhattacharyya N, Dey A, Minucci S, Zimmer A, John S, Hager G, Ozato K: Retinoid-induced chromatin structure alterations in the retinoic acid receptor beta2 promoter. Mol Cell Biol 1997, 17:6481-6490. 
17. Langston AW, Thompson JR, Gudas L: Retinoic acid-responsive enhancers located 3' of the Hox A and Hox B homeobox gene clusters. Functional analysis. J Biol Chem 1997, 272:2167-2175.

18. Lohnes D, Kastner P, Dierich A, Mark M, LeMeur M, Chambon P: Function of retinoic acid receptor gamma in the mouse. Cell 1993, 73:643-658

19. Lufkin T, Lohnes D, Mark M, Dierich A, Gorry P, Gaub MP, LeMeur M, Chambon $P$ : High postnatal lethality and testis degeneration in retinoic acid receptor alpha mutant mice. Proc Natl Acad Sci USA 1993, 90:7225-7229.

20. Grondona JM, Kastner P, Gansmuller A, Decimo D, Chambon P, Mark M: Retinal dysplasia and degeneration in RARbeta2/RARgamma2 compound mutant mice. Development 1996, 122:2173-2188.

21. Lohnes D, Mark M, Mendelsohn C, Dolle P, Dierich A, Gorry P, Gansmuller A, Chambon P: Function of the retinoic acid receptors (RARs) during development (I). Craniofacial and skeletal abnormalities in RAR double mutants. Development 1994, 120:2723-2748.

22. Wendling $O$, Ghyselinck NB, Chambon P, Mark M: Roles of retinoic acid receptors in early embryonic morphogenesis and hindbrain patterning. Development 2001, 128:2031-2038.

23. Wendling O, Dennefeld C, Chambon P, Mark M: Retinoid signaling is essential for patterning the endoderm of the third and fourth pharyngeal arches. Development 2000, 127:1553-1562.

24. Kastner P, Grondona JM, Mark M, Gansmuller A, LeMeur M, Decimo D, Vonesch $J L$, Dolle P, Chambon P: Genetic analysis of RXR alpha developmental function: convergence of RXR and RAR signaling pathways in heart and eye morphogenesis. Cell 1994, 78:987-1003.

25. Krezel W, Dupe V, Mark M, Dierich A, Kastner P, Chambon P: RXR gamma null mice are apparently normal and compound RXR alpha $+/-/$ RXR beta -/-/RXR gamma -/- mutant mice are viable. Proc Natl Acad Sci USA 1996, 93:9010-9014.

26. Sucov HM, Dyson E, Gumeringer CL, Price J, Chien KR, Evans RM: RXR alpha mutant mice establish a genetic basis for vitamin A signaling in heart morphogenesis. Genes Dev 1994, 8:1007-1018.

27. Sapin V, Dolle P, Hindelang C, Kastner P, Chambon P: Defects of the chorioallantoic placenta in mouse RXRalpha null fetuses. Dev Biol 1997, 191:29-41.

28. Kastner P, Mark M, Ghyselinck N, Krezel W, Dupe V, Grondona JM, Chambon $P$ : Genetic evidence that the retinoid signal is transduced by heterodimeric RXR/RAR functional units during mouse development. Development 1997, 124:313-326.

29. Wendling $O$, Chambon $P$, Mark M: Retinoid X receptors are essential for early mouse development and placentogenesis. Proc Natl Acad Sci USA 1999, 96:547-551.

30. Tanaka T, De Luca LM: Therapeutic potential of "rexinoids" in cancer prevention and treatment. Cancer Res 2009, 69:4945-4947.

31. Ahuja HS, Szanto A, Nagy L, Davies PJ: The retinoid $X$ receptor and its ligands: versatile regulators of metabolic function, cell differentiation and cell death. J Biol Regul Homeost Agents 2003, 17:29-45.

32. Heintzman ND, Ren B: Finding distal regulatory elements in the human genome. Curr Opin Genet Dev 2009, 19:541-549.

33. Wolffe AP: Histones, nucleosomes and the roles of chromatin structure in transcriptional control. Biochem Soc Trans 1997, 25:354-358.

34. Orkin SH, Hochedlinger K: Chromatin connections to pluripotency and cellular reprogramming. Cell 2011, 145:835-850.

35. Guenther MG, Levine SS, Boyer LA, Jaenisch R, Young RA: A chromatin landmark and transcription initiation at most promoters in human cells. Cell 2007, 130:77-88.

36. Heintzman ND, Stuart RK, Hon G, Fu Y, Ching CW, Hawkins RD, Barrera LO, Van Calcar S, Qu C, Ching KA, Wang W, Weng Z, Green RD, Crawford GE, Ren B: Distinct and predictive chromatin signatures of transcriptional promoters and enhancers in the human genome. Nat Genet 2007 39:311-318.

37. Asp P, Blum R, Vethantham V, Parisi F, Micsinai M, Cheng J, Bowman C, Kluger $Y$, Dynlacht BD: Genome-wide remodeling of the epigenetic landscape during myogenic differentiation. Proc Natl Acad Sci USA 2011, 108:E149-158.

38. Visel A, Blow MJ, Li Z, Zhang T, Akiyama JA, Holt A, Plajzer-Frick I, Shoukry M, Wright C, Chen F, Afzal V, Ren B, Rubin EM, Pennacchio LA: ChIP-seq accurately predicts tissue-specific activity of enhancers. Nature 2009, 457:854-858.

39. Dorschner MO, Hawrylycz M, Humbert R, Wallace JC, Shafer A, Kawamoto J, Mack J, Hall R, Goldy J, Sabo PJ, Kohli A, Li Q, McArthur M,
Stamatoyannopoulos JA: High-throughput localization of functional elements by quantitative chromatin profiling. Nat Methods 2004, 1:219-225.

40. Berkes CA, Tapscott SJ: MyoD and the transcriptional control of myogenesis. Semin Cell Dev Biol 2005, 16:585-595.

41. Tajbakhsh S, Rocancourt D, Cossu G, Buckingham M: Redefining the genetic hierarchies controlling skeletal myogenesis: Pax-3 and Myf-5 act upstream of MyoD. Cell 1997, 89:127-138.

42. Francetic T, Li Q: Skeletal myogenesis and Myf5 activation. Transcription 2011, 2:109-114

43. Roth JF, Shikama N, Henzen C, Desbaillets I, Lutz W, Marino S, Wittwer J, Schorle H, Gassmann M, Eckner R: Differential role of p300 and CBP acetyltransferase during myogenesis: p300 acts upstream of MyoD and Myf5. Embo J 2003, 22:5186-5196.

44. Martin GR, Evans MJ: The morphology and growth of a pluripotent teratocarcinoma cell line and its derivatives in tissue culture. Cell 1974, 2:163-172.

45. Martin GR, Evans MJ: Differentiation of clonal lines of teratocarcinoma cells: formation of embryoid bodies in vitro. Proc Natl Acad Sci USA 1975, 72:1441-1445

46. Le May M, Mach H, Lacroix N, Hou C, Chen J, Li Q: Contribution of Retinoid $X$ Receptor Signaling to the Specification of Skeletal Muscle Lineage. J Biol Chem 2011, 286:26806-26812

47. McBurney MW, Rogers BJ: Isolation of male embryonal carcinoma cells and their chromosome replication patterns. Dev Biol 1982, 89:503-508.

48. Vidricaire G, Jardine K, McBurney MW: Expression of the Brachyury gene during mesoderm development in differentiating embryonal carcinoma cell cultures. Development 1994, 120:115-122.

49. McBurney MW, Jones-Villeneuve EM, Edwards MK, Anderson PJ: Control of muscle and neuronal differentiation in a cultured embryonal carcinoma cell line. Nature 1982, 299:165-167.

50. Edwards MK, McBurney MW: The concentration of retinoic acid determines the differentiated cell types formed by a teratocarcinoma cell line. Dev Biol 1983, 98:187-191.

51. Edwards MK, Harris JF, McBurney MW: Induced muscle differentiation in an embryonal carcinoma cell line. Mol Cell Biol 1983, 3:2280-2286.

52. Jones-Villeneuve EM, Rudnicki MA, Harris JF, McBurney MW: Retinoic acidinduced neural differentiation of embryonal carcinoma cells. Mol Cell Biol 1983, 3:2271-2279.

53. Kennedy KA, Porter T, Mehta V, Ryan SD, Price F, Peshdary V, Karamboulas C, Savage J, Drysdale TA, Li SC, Bennett SA, Skerjanc IS: Retinoic acid enhances skeletal muscle progenitor formation and bypasses inhibition by bone morphogenetic protein 4 but not dominant negative betacatenin. BMC Biol 2009, 7:67.

54. Armour C, Garson K, McBurney MW: Cell-cell interaction modulates myoDinduced skeletal myogenesis of pluripotent P19 cells in vitro. Exp Cell Res 1999, 251:79-91.

55. Evans MJ, Kaufman MH: Establishment in culture of pluripotential cells from mouse embryos. Nature 1981, 292:154-156.

56. Martin GR: Isolation of a pluripotent cell line from early mouse embryos cultured in medium conditioned by teratocarcinoma stem cells. Proc Natl Acad Sci USA 1981, 78:7634-7638

57. Doetschman TC, Eistetter H, Katz M, Schmidt W, Kemler R: The in vitro development of blastocyst-derived embryonic stem cell lines: formation of visceral yolk sac, blood islands and myocardium. J Embryol Exp Morphol 1985, 87:27-45.

58. Williams RL, Hilton DJ, Pease S, Willson TA, Stewart CL, Gearing DP, Wagne EF, Metcalf D, Nicola NA, Gough NM: Myeloid leukaemia inhibitory factor maintains the developmental potential of embryonic stem cells. Nature 1988, 336:684-687.

59. Smith AG, Heath JK, Donaldson DD, Wong GG, Moreau J, Stahl M, Rogers D: Inhibition of pluripotential embryonic stem cell differentiation by purified polypeptides. Nature 1988, 336:688-690.

60. Rohwedel J, Maltsev V, Bober E, Arnold HH, Hescheler J, Wobus AM: Muscle cell differentiation of embryonic stem cells reflects myogenesis in vivo: developmentally regulated expression of myogenic determination genes and functional expression of ionic currents. Dev Biol 1994, 164:87-101.

61. Wobus AM, Rohwedel J, Maltsev V, Hescheler J: In vitro differentiation of embryonic stem cells into cardiomyocytes or skeletal muscle cells is specifically modulated by retinoic acid. Roux's Arch Dev Biol 1994, 204:36-45.

62. Bajard L, Relaix F, Lagha M, Rocancourt D, Daubas P, Buckingham ME: A novel genetic hierarchy functions during hypaxial myogenesis: Pax3 
directly activates Myf5 in muscle progenitor cells in the limb. Genes Dev 2006, 20:2450-2464

63. Seale P, Sabourin LA, Girgis-Gabardo A, Mansouri A, Gruss P, Rudnicki MA: Pax7 is required for the specification of myogenic satellite cells. Cell 2000, 102:777-786.

64. Kassar-Duchossoy L, Giacone E, Gayraud-Morel B, Jory A, Gomes D, Tajbakhsh S: Pax3/Pax7 mark a novel population of primitive myogenic cells during development. Genes Dev 2005, 19:1426-1431.

65. Relaix F, Rocancourt D, Mansouri A, Buckingham M: A Pax3/Pax7dependent population of skeletal muscle progenitor cells. Nature 2005, 435:948-953.

66. Darabi R, Gehlbach K, Bachoo RM, Kamath S, Osawa M, Kamm KE, Kyba M, Perlingeiro RC: Functional skeletal muscle regeneration from differentiating embryonic stem cells. Nat Med 2008, 14:134-143.

67. Darabi R, Santos FN, Filareto A, Pan W, Koene R, Rudnicki MA, Kyba M, Perlingeiro RC: Assessment of the myogenic stem cell compartment following transplantation of Pax3/Pax7-induced embryonic stem cellderived progenitors. Stem Cells 2011, 29:777-790.

68. Ridgeway AG, Skerjanc IS: Pax3 is essential for skeletal myogenesis and the expression of Six1 and Eya2. J Biol Chem 2001, 276:19033-19039.

69. Petropoulos H, Gianakopoulos PJ, Ridgeway AG, Skerjanc IS: Disruption of Meox or Gli activity ablates skeletal myogenesis in P19 cells. J Biol Chem 2004, 279:23874-23881.

70. Francetic T, Le May M, Hamed M, Mach H, Meyers D, Cole PA, Chen J, Li Q: Regulation of Myf5 early enhancer by histone acetyltransferase p300 during stem cell differentiation. Mol Biol 2012, 1:103.

71. Hamed M, Khilji S, Chen J, Li Q: Stepwise acetyltransferase association and histone acetylation at the Myod 1 locus during myogenic differentiation. Sci Rep 2013, 3:2390.

72. Cerletti M, Jurga S, Witczak CA, Hirshman MF, Shadrach JL, Goodyear LJ, Wagers AJ: Highly efficient, functional engraftment of skeletal muscle stem cells in dystrophic muscles. Cell 2008, 134:37-47.

73. Sacco A, Doyonnas R, Kraft P, Vitorovic S, Blau HM: Self-renewal and expansion of single transplanted muscle stem cells. Nature 2008, 456:502-506.

74. Montarras D, Morgan J, Collins C, Relaix F, Zaffran S, Cumano A, Partridge T, Buckingham M: Direct isolation of satellite cells for skeletal muscle regeneration. Science 2005, 309:2064-2067.

75. Shi X, Garry DJ: Muscle stem cells in development, regeneration, and disease. Genes Dev 2006, 20:1692-1708.

doi:10.1186/2045-3701-3-40

Cite this article as: Chen and Li: Enhancing myogenic differentiation of pluripotent stem cells with small molecule inducers. Cell \& Bioscience 2013 3:40.

\section{Submit your next manuscript to BioMed Central and take full advantage of:}

- Convenient online submission

- Thorough peer review

- No space constraints or color figure charges

- Immediate publication on acceptance

- Inclusion in PubMed, CAS, Scopus and Google Scholar

- Research which is freely available for redistribution 